\title{
Primary care management of allergic rhinitis: a cross-sectional study in four ASEAN countries
}

\author{
Baharudin Abdullah, ${ }^{1}$ Kornkiat Snidvongs, ${ }^{2}$ Marysia Recto, ${ }^{3}$ Niken Lestari Poerbonegoro, ${ }^{4}$ De Yun Wang ${ }^{5}$ \\ ${ }^{1}$ Department of Otorhinolaryngology - Head and Neck Surgery, School of Medical Sciences, Universiti Sains Malaysia, \\ Kelantan, Malaysia \\ ${ }^{2}$ Endoscopic Nasal and Sinus Surgery Excellence Center Chulalongkorn Hospital, Department of Otolaryngology, Faculty of \\ Medicine, Chulalongkorn University, Thailand \\ ${ }^{3}$ Adult and Pediatric Division of Allergy and Immunology, University of the Philippines - Philippine General Hospital, \\ Manila, Philippenes \\ ${ }^{4}$ Department of Otorhinolaryngology-Head and Neck Surgery, Faculty of Medicine Universitas Indonesia/Dr. Cipto \\ Mangunkusumo Hospital, Jakarta \\ ${ }^{5}$ Department of Otolaryngology, Yong Loo Lin School of Medicine, National University of Singapore, Singapore
}

Background: In primary care, general practitioners (GPs) and pharmacists are tasked with the frontline responsibility of identifying and managing allergic rhinitis (AR) patients. There are currently no consolidated data on current treatment practices, patient compliance, and usage of guidelines within Southeast Asian Nations (ASEAN).

Objective: To assess the attitudes and practices on AR of GPs and pharmacists in 4 ASEAN countries (Philippines, Indonesia, Thailand, and Malaysia).

Methods: A cross-sectional survey of 329 GPs and 548 pharmacists was conducted from May to November 2019. Participants answered a questionnaire focused on their i) current practice in the management of AR, ii) views on patient compliance, iii) understanding and usage of guidelines.

Results: Clinical history was the most preferred method to diagnose AR by $95.4 \%$ of GPs and $58.8 \%$ of pharmacists. Second-generation antihistamines were the most widely available treatment option in GP clinics and pharmacies (94.8\% and $97.2 \%$ ) and correspondingly the most preferred treatment for both mild $(90.3 \%, 76.8 \%)$ to moderatesevere rhinitis $(90.3 \%, 78.6 \%)$ by GPs and pharmacists, respectively. Loratadine was ranked as the most preferred $2^{\text {nd }}$ generation antihistamines (GP vs pharmacists: $55.3 \%$ vs 58.9\%). More than $90 \%$ of GPs and pharmacists ranked length and efficacy of treatment as important factors that increase patient compliance. Awareness of the ARIA guidelines was high among GPs (80\%) and lower among pharmacists (48.4\%). However, only $63.3 \%$ of GPs and $48.2 \%$ of pharmacists knew how to identify AR patients.

Conclusions: The survey in the 4 ASEAN countries has identified a need to strengthen the awareness and use of ARIA guidelines among the primary care practitioners. Adherence to ARIA guidelines, choosing the appropriate treatment option and prioritizing factors that increases patient compliance may contribute to better management outcomes of AR at the primary care practice

Key words: Allergic rhinitis; management; ASEAN; primary care; general practitioners; multidisciplinary.

Correspondence: Professor Baharudin Abdullah, Department of Otorhinolaryngology - Head and Neck Surgery, School of Medical Sciences, Universiti Sains Malaysia, 16150 Kubang Kerian, Kelantan, Malaysia.

Tel. +60.97676416 - Fax: +60.97676424. E-mail: baharudin@usm.my

Contributions: All the authors made a substantive intellectual contribution. All the authors have read and approved the final version of the manuscript and agreed to be accountable for all aspects of the work.

Conflict of interest: All authors declare no conflict of interest.

Financial support: Bayer Consumer Health ASEAN (Malaysia, Thailand, Philippines, Indonesia) provided logistic support in organizing the education symposiums where the surveys were conducted. Bayer Co. (Malaysia) Sdn. Bhd. further provided support in respect of publication costs but had no influence on the content of the work.

Availability of data and materials: The data used to support the findings of this study are available from the corresponding author upon request.

Ethic approval and consent to participate: Ethical approval was obtained from Human Research Ethics Committee USM (Universiti Sains Malaysia) (USM/JEPeM/ 19050284).

Consent for publication: Not applicable. 


\section{Introduction}

Allergic rhinitis (AR) is defined as an IgE-mediated symptomatic disorder of the nose induced after allergen exposure [1]. AR affects approximately $40 \%$ of the population globally, with prevalence rates on the rise and records the highest ones in the Asia Pacific [2,3]. As of 2011, the prevalence is reported to be $8.7 \%$ across eight Asia Pacific regions [3]. A survey conducted in Singapore revealed that AR was the key complaint of patients (10$40 \%$ ) visiting primary care clinics [4]. With this high patient load, it becomes pertinent to establish a strong healthcare ecosystem, comprising of a spectrum of healthcare professionals - specialists, general practitioners (GPs) and pharmacists, to come together and optimize AR management. In the primary care environment, GPs and pharmacists are key healthcare providers. GPs are responsible for diagnosis, treatment recommendations and patient counselling. Pharmacists, on the other hand, are responsible for dispense of medications and identification of AR patients for further referral and diagnosis by doctors. With overlap symptoms amongst AR and colds, as well as increasing availability of over-the-counter (OTC) drugs in AR management, pharmacists' understanding in AR management and identification of AR patients becomes a critical step in the healthcare ecosystem for AR management [1].

The allergic rhinitis and its impact on asthma (ARIA) guidelines aim to provide evidence-based recommendations to clinicians for the management of AR and asthma [1,5]. It has previously been reported that adherence to guidelines such as ARIA for the treatment of AR yielded better patient outcomes [6]. Nonetheless, despite the recognized importance of guidelines, current literature pinpoints to low-level awareness on the ARIA guidelines among both the GPs and pharmacists [7]. Consistently, within the Asia Pacific, another survey conducted on more than 500 Malaysian GPs; ear, nose, and throat (ENT) specialists and pharmacists demonstrated that $42 \%$ of the pharmacists and $11 \%$ of the GPs were not satisfied with ARIA guidelines mainly due to the lack of stepwise guidance for management of AR in the primary care setting. This study also revealed that antihistamines remained the most preferred choice for mild AR treatment, as recommended by $51 \%$ GPs, $45 \%$ ENT specialists, and 78\% pharmacists [8].

Most recently, an expert consensus article from Malaysia identified gaps between the current guidelines and real-world practice, with emphasis at the primary management level. Specific to antihistamine treatments, the authors presented guidance for primary care practitioners by introducing a three-step approach: i) profile each patient; ii) review patient-specific considerations based on profile; iii) recommend and monitor treatment responses and always escalate up to specialist care in more severe or difficult-totreat cases [9].

Compared to other regions of the world, data on primary care attitudes and practices in the management of AR is still limited in the Association of Southeast Asian Nations (ASEAN). To close this gap, focusing on primary care in Malaysia, Indonesia, Philippines, and Thailand, our study seeks to better understand primary care in terms of: i) their current practice in the management of AR in primary care; ii) their views on patient compliance; and iii) their understanding and usage of guidelines.

\section{Methods}

\section{Subjects}

This cross-sectional survey involving GPs and pharmacists, in four ASEAN countries (Philippines, Indonesia, Thailand, and Malaysia) was conducted from May to November 2019. Ethical approval was obtained from Human Research Ethics Committee USM (USM/JEPeM/ 19050284). Each survey was conducted before allergy-focused education symposiums and workshops. We used a probability-based sampling methodology to obtain a representative national sample of GPs and pharmacists across regions in each country, comprising approximately 100 GPs and 100 pharmacists per country (50\% GPs and 50\% pharmacists) giving a total target sample size of 800 . A total of 902 responses were received, of which 887 (GPs: 329, pharmacists: 548) were considered. The reason for any exclusion of responses from the data analysis was profession other than primary care practice.

\section{Questionnaire}

The questionnaire for this study entitled 'ASEAN Primary Care Survey for Allergy Rhinitis Care' was designed, following previously conducted survey publications $[8,10,11]$. It consisted of 32 questions divided into five sections:

1. Demographics/Screener

2. Pharmacy practice/clinical practice followed

3. Perception of antihistamines in primary care

4. Understanding of AR and the guidelines

5. Understanding of ARIA guidelines

The questionnaire was uploaded on an online platform using the Google form (https:/www.google.com/forms/about/) and had a statement at the beginning, briefing participants about the purpose of conducting this survey. No personal data was collected during this survey study. The link of the survey was shared with participants at allergy-focused education symposiums and workshops.

\section{Statistical analysis}

After the closure of access to the survey, the data for each country survey was downloaded directly from Google Forms in the Microsoft ${ }^{\circ}$ Excel form. The data on responses of GPs and pharmacists for each country were extracted, and then the data were clustered for all the four ASEAN countries for GP and pharmacists. For evaluation of the responses to all survey questions, the count and percentages of each option of the questions were calculated. There were some questions in the survey where participants may select more than one option. Categorical data was analyzed using the Chi-square/Fisher exact test, and the continuous data variables were assessed with a $t$-test for two independent variables/MannWhitney $U$ test depending upon the distribution of the data. T-test was used for two independent samples with normal distribution while Mann-Whitney U test was used for data with huge variation (not-normally distributed data). Statistical significance was assessed at $\mathrm{p}<0.05$ adjusted with Bonferroni correction for multiple tests. SPSS v23.0 software was used for data analysis.

\section{Results}

\section{Characteristics of respondents}

In the 'GPs' group, all respondents are certified medical doctors who see patients in the community. Taken together, they see a median of 100 patients/week. The clinical experience and additional profile details of participants are given in Table 1 . In the 'Pharmacists' group, most of the respondents were retail and community pharmacists $(83 \%)$, while a few were hospital pharmacists $(14 \%)$. The pharmacists see a median 200 patients/week $(\mathrm{p}<0.001)$. The clinical experience and additional profile details of the participating pharmacists are given in Table 1. 


\section{Diagnosis of allergic rhinitis}

Overall, 95\% percent of the GPs and $58.8 \%$ of pharmacists used clinical history to identify AR patients $(p<0.001)$. Less than $15 \%$ of GPs chose other diagnostic techniques such as imaging paranasal sinuses, and nasal endoscopy. In comparison, because pharmacists are not professionally trained to diagnose the condition, less than $10 \%$ of pharmacists utilized diagnosis methods such as anterior rhinoscopy, allergy testing, imaging paranasal sinuses and nasal endoscopy, and only $48.2 \%$ of pharmacists responded that they knew how to identify AR patients (Table 2).

\section{Treatment of allergic rhinitis}

In both GP clinics and pharmacies, there is a good range of treatment options for $\mathrm{AR}$, comprising of single and combination drugs, as well as non-drug options such as saline douching. Noteworthy, almost all GP clinics and pharmacies have $1^{\text {st }}$ and $2^{\text {nd }}$ generation antihistamines in stock, and nearly all pharmacies have the combination of oral antihistamines and decongestants in stock. This is indicated by agreement levels of more than $90 \%$ respond- ing "yes" to all listed treatment options. Corresponding to treatment availability, $2^{\text {nd }}$ generation antihistamines are the most preferred treatment option for AR patients regardless of disease severity, as selected by both GPs and pharmacists responding "always recommend" based on the listed treatment options $(90.2 \%$ and $76.3 \%$ for mild AR; $90.2 \%$ and $78.6 \%$ for moderate-severe AR patients), respectively. This was statistically more significant than $1^{\text {st }}$ generation antihistamines or the combination of oral antihistamines and decongestants $(\mathrm{p}<0.001)$. For moderate-severe AR patients compared to mild AR patients, there is also an increased preference among GPs to recommend intranasal corticosteroids $(67.8 \%$ vs. $40.1 \%)$ and the combination of oral antihistamines and decongestants $(68.1 \%$ vs $59 \%)$. Non-drug treatment are also preferred treatment options for both mild and moderate-severe AR patients including saline douching (46.1\% and 53\% for GP; $42 \%$ and $48.5 \%$ for pharmacist) and allergen avoidance $(71 \%$ and $71.3 \%$ for GP; $57.7 \%$ and $58.4 \%$ for pharmacist). Taken together, these data demonstrate that antihistamines, particularly $2^{\text {nd }}$ generation antihistamines, are still the mainstay of AR treatment in primary care practice within ASEAN. With $2^{\text {nd }}$ generation antihis-

Table 1. Demographics details of the respondents who participated in this survey study.

\begin{tabular}{|c|c|c|c|c|c|}
\hline Profile & Malaysia & Thailand & Philippines & Indonesia & Total (N) \\
\hline \multicolumn{6}{|l|}{ General practitioners / Medical doctors } \\
\hline $\mathrm{N}$ of respondents, $\mathrm{n}(\%)$ & $57(100)$ & $89(100)$ & $108(100)$ & $63(100)$ & 317 \\
\hline $\begin{array}{l}\text { Composition, } n(\%) \\
\text { Years of practice, } n(\%) \\
<5 \text { years } \\
5-10 \text { years } \\
11-20 \text { years } \\
>20 \text { years }\end{array}$ & $\begin{array}{l}1(1.8) \\
6(10.5) \\
21(36.8) \\
29(50.9)\end{array}$ & $\begin{array}{l}63(70.8) \\
19(21.4) \\
6(6.7) \\
1(1.1)\end{array}$ & $\begin{array}{l}41(37.9) \\
35(32.4) \\
21(19.4) \\
11(10.2)\end{array}$ & $\begin{array}{l}19(30.1) \\
11(17.5) \\
23(36.5) \\
10(15.9)\end{array}$ & $\begin{array}{l}132 \\
75 \\
71 \\
51\end{array}$ \\
\hline $\begin{array}{l}\text { Place of practice, } n(\%) \\
\quad \text { Private sector } \\
\text { Public sector }\end{array}$ & $\begin{array}{c}54(94.7) \\
3(5.3)\end{array}$ & $\begin{array}{c}8(9) \\
81(91)\end{array}$ & $\begin{array}{l}70(64.8) \\
38(35.2)\end{array}$ & $\begin{array}{l}34(54) \\
29(46)\end{array}$ & $\begin{array}{l}177 \\
152\end{array}$ \\
\hline Median number of patients seen/week (range), IQR & $150(7-501), 200$ & $150(1-500), 180$ & $60(3-1000), 70$ & $100(6-700), 120$ & $100(1-1000), 160$ \\
\hline Median number of patients with AR seen/week (range), IQR & $20(0-2020), 23$ & $10(1-80), 15$ & $10(0-60), 15$ & $10(1-100), 10$ & $10(0-2020), 15$ \\
\hline Median number of patients with asthma seen/week (range), IQR & $7(0-77), 14$ & $3(0-50), 11$ & $9(0-120), 10$ & $5(0-100), 8$ & $5(0-120), 8$ \\
\hline $\begin{array}{l}\text { Median number of patients with both AR and asthma seen/week } \\
\text { (range), IQR }\end{array}$ & $5(0-70), 8$ & $5(0-50), 9$ & $5(0-100), 7$ & $2(0-100), 4$ & $5(0-100), 8$ \\
\hline Pharmacists & & & & & \\
\hline N. of respondents (\%) & $194(100)$ & $39(100)$ & $216(100)$ & $99(100)$ & 548 \\
\hline $\begin{array}{l}\text { Composition (\%) } \\
\text { Retail/community pharmacist } \\
\text { Hospital pharmacist }\end{array}$ & $\begin{array}{l}141(72.7) \\
53(27.3)\end{array}$ & $\begin{array}{l}29(74.4) \\
10(25.6)\end{array}$ & $\begin{array}{c}206(95.4) \\
10(4.6)\end{array}$ & $\begin{array}{l}96(97) \\
3(3.1)\end{array}$ & $\begin{array}{l}472 \\
76\end{array}$ \\
\hline $\begin{array}{l}\text { Years of practice, } n(\%) \\
\quad<5 \text { years } \\
5-10 \text { years } \\
10-20 \text { years } \\
>20 \text { years }\end{array}$ & $\begin{array}{l}85(43.8) \\
52(26.8) \\
40(20.6) \\
17(8.8)\end{array}$ & $\begin{array}{l}12(30.8) \\
17(43.6) \\
10(25.6) \\
-\end{array}$ & $\begin{array}{l}97(44.9) \\
58(26.9) \\
35(16.2) \\
26(12)\end{array}$ & $\begin{array}{l}84(84.9) \\
12(12.1) \\
1(1) \\
2(2)\end{array}$ & $\begin{array}{l}278 \\
139 \\
86 \\
45\end{array}$ \\
\hline $\begin{array}{l}\text { Place of practice, } n(\%) \\
\text { Private sector } \\
\text { Public sector } \\
\text { Median number of patients seen/week (range), IQR } \\
\text { Median number of patients with AR seen/week (range), IQR } \\
\text { Median number of patients with asthma seen/week (range), IQR } \\
\text { Median number of patients with both AR and asthma seen/week } \\
\text { (range), IQR }\end{array}$ & $\begin{array}{c}134(69.0) \\
60(31.0) \\
150(0-4000), 335 \\
30(0-1500), 60 \\
20(0-1000), 34 \\
10(0-500), 20\end{array}$ & $\begin{array}{c}30(76.9) \\
9(23.1) \\
300(7-1500), 420 \\
40(0-350), 70 \\
10(0-150), 25 \\
10(0-100), 16\end{array}$ & $\begin{array}{c}189(87.5) \\
27(12.5) \\
150(4-10000), 200 \\
30(2-2000), 70 \\
30(1-2000), 50 \\
25(2-2000), 39\end{array}$ & $\begin{array}{c}4(4) \\
95(96) \\
400(7-2000), 550 \\
30(1-300), 45 \\
10(1-200), 45 \\
10(0-300), 22\end{array}$ & $\begin{array}{c}357 \\
191 \\
200(0-10000)^{*}, 300 \\
30(0-2000)^{*}, 70 \\
20(0-2000)^{*}, 40 \\
15(0-2000)^{*}, 25\end{array}$ \\
\hline
\end{tabular}


tamines selected as the most preferred treatment option for AR patients (mild to severe) in primary care practice both GPs and pharmacists agreed that antihistamines are always effective in the treatment of patients with mild-moderate AR $(91.8 \%$ and $92 \%)$, respectively. It is further demonstrated that out of the six commonly-available $2^{\text {nd }}$ generation antihistamines in ASEAN, loratadine is ranked as the most preferred choice amongst GPs and pharmacists $(55.2 \% \%$ and $58.9 \%)$. This is followed by cetirizine $(41 \%$ and $40.5 \%)$. When it comes to primary care considerations prior to the recommendation of antihistamines, GPs are mostly concerned with the efficacy of the drug (94.6\%), whilst pharmacists are further concerned with use during pregnancy and breastfeeding $(91.6 \%)$ and side effects such as somnolence $(90 \%)$, aside from efficacy of drug $(96.7 \%)$

\section{Patient compliance and management in primary care practice}

From a predetermined list of factors, both GPs (Figure 1A) and pharmacists (Figure 2B) in Malaysia, Philippines, Thailand and Indonesia listed length of treatment (95.9\% and 93.4\%), treatment efficacy $(94.1 \%$ and $94.7 \%)$ and route of administration $(91.8 \%$ and $92.2 \%$ ) as the top 3 factors influencing patient's compliance to AR treatment. Noteworthy, majority of the pharmacists think that patients' phobia of steroids (72.6\% pharmacists vs $62.5 \%$ GPs; $\mathrm{p}<0.001)$ is the other key factor influencing patient compliance (Figure $1 \mathrm{~A}, \mathrm{~B}$ ).
With a preliminary understanding of primary care practice, a question was included in the survey on 'what else is needed to optimize AR management in primary care'. A predetermined list of factors was provided to respondents: i) accurate diagnosis of AR; ii) availability of allergy testing; iii) allergen avoidance measures; iv) disease awareness and health education for patients; v) accessibility and cost of treatment; vi) recommended length of treatment; vii) dedicated guidelines for primary care. More than $90 \%$ of both GPs and pharmacists agreed that all these factors, except for (ii) availability of allergy testing, are needed to optimize AR management in primary care practice (Figure 2 A,B). Specific to allergy testing, it is noteworthy that more pharmacists agreed that this factor is needed, as compared to GPs ( $84.3 \%$ of pharmacists $v s 63.8 \%$ of GPs; $p<0.001$ ) (Figure $2 \mathrm{~A}, \mathrm{~B}$ ). This corresponds to less than half of both GPs and pharmacists agreeing that specific allergy testing is necessary to distinguish between AR and non-AR conditions (45.7\% vs $47.6 \%)$, respectively (Table 2 ).

\section{Awareness and perception of guidelines in primary care practice}

Within Malaysia, Philippines, Thailand and Indonesia, the authors are well aware that GPs play a major role in diagnosis of AR, which explain more GPs than pharmacists (80.8 \% vs 48.4\%; $\mathrm{p}<0.001)$ are aware of the ARIA guidelines that govern treatment recommendations for patients diagnosed with AR (Table 2). This level of awareness was similar for the Global Initiative for Asthma

Table 2. General practitioners and pharmacists' agreement on statements pertaining to their understanding and management of allergic rhinitis. The percentage of respondents who chose "Agree", "Neutral" or "Disagree" to specific questions asked is shown.

\begin{tabular}{|c|c|c|c|c|}
\hline & Responses & $\begin{array}{c}\text { GP n (\%) } \\
N=317\end{array}$ & $\begin{array}{l}\text { Pharmacists n (\%) } \\
\quad \mathrm{N}=548\end{array}$ & $\begin{array}{c}\text { p, } \\
\text { comparing GP } \\
\text { to pharmacists }\end{array}$ \\
\hline Do you know ARIA guidelines? & $\begin{array}{l}\text { Yes } \\
\text { No } \\
\text { Not Sure }\end{array}$ & $\begin{array}{c}256(80.8) \\
22(6.9) \\
39(12.3)\end{array}$ & $\begin{array}{l}265(48.4) \\
115(20.9) \\
168(30.7)\end{array}$ & $<0.001$ \\
\hline Do you know GINA guidelines? & $\begin{array}{l}\text { Yes } \\
\text { No } \\
\text { Not Sure }\end{array}$ & $\begin{array}{c}242(76.3) \\
25(7.9) \\
50(15.8)\end{array}$ & $\begin{array}{c}223(40.7) \\
144(26.3) \\
181(33)\end{array}$ & $<0.001$ \\
\hline Do you know other guidelines for AR? & $\begin{array}{l}\text { Yes } \\
\text { No } \\
\text { Not Sure }\end{array}$ & $\begin{array}{c}56(17.7) \\
118(37.2) \\
143(45.1)\end{array}$ & $\begin{array}{c}47(8.6) \\
208(38) \\
293(53.5)\end{array}$ & $<0.001$ \\
\hline Do you know rhinitis can be classified into AR and non-AR? & $\begin{array}{l}\text { Yes } \\
\text { No } \\
\text { Not Sure }\end{array}$ & $\begin{array}{c}215(67.8) \\
42(13.2) \\
60(18.9)\end{array}$ & $\begin{array}{c}270(49.3) \\
98(17.9) \\
180(32.8)\end{array}$ & $<0.001$ \\
\hline Is specific allergy testing necessary to distinguish between AR and non-AR? & $\begin{array}{l}\text { Yes } \\
\text { No } \\
\text { Not Sure }\end{array}$ & $\begin{array}{c}145(45.7) \\
76(24) \\
96(30.3)\end{array}$ & $\begin{array}{c}261(47.6) \\
82(15) \\
205(37.4)\end{array}$ & $<0.001$ \\
\hline In your opinion, is an evaluation of asthma necessary for AR patients? & $\begin{array}{l}\text { Yes } \\
\text { No } \\
\text { Not sure }\end{array}$ & $\begin{array}{c}254(80.1) \\
20(6.3) \\
43(13.6)\end{array}$ & $\begin{array}{c}356(65) \\
53(9.6) \\
139(25.4)\end{array}$ & $<0.001$ \\
\hline Do you know how to identify AR patients? & $\begin{array}{l}\text { Yes } \\
\text { No } \\
\text { Not sure }\end{array}$ & $\begin{array}{c}259(81.7) \\
10(3.2) \\
48(15.1)\end{array}$ & $\begin{array}{c}264(48.2) \\
85(15.5) \\
199(36.3)\end{array}$ & $<0.001$ \\
\hline Do you know the common symptoms of AR? & $\begin{array}{l}\text { Yes } \\
\text { No } \\
\text { Not sure }\end{array}$ & $\begin{array}{c}286(90.2) \\
4(1.3) \\
27(8.5)\end{array}$ & $\begin{array}{c}380(69.3) \\
43(7.8) \\
125(22.8)\end{array}$ & $<0.001$ \\
\hline Do you know how to classify allergic rhinitis based on severity? & $\begin{array}{l}\text { Yes } \\
\text { No } \\
\text { Not sure }\end{array}$ & $\begin{array}{c}236(74.4) \\
26(8.2) \\
55(17.4)\end{array}$ & $\begin{array}{l}236(43.1) \\
100(18.2) \\
212(38.7)\end{array}$ & $<0.001$ \\
\hline
\end{tabular}

AR, Allergic rhinitis; ARIA, allergic rhinitis and its impact on asthma; GINA, global initiative for asthma; GP, general practitioner. 


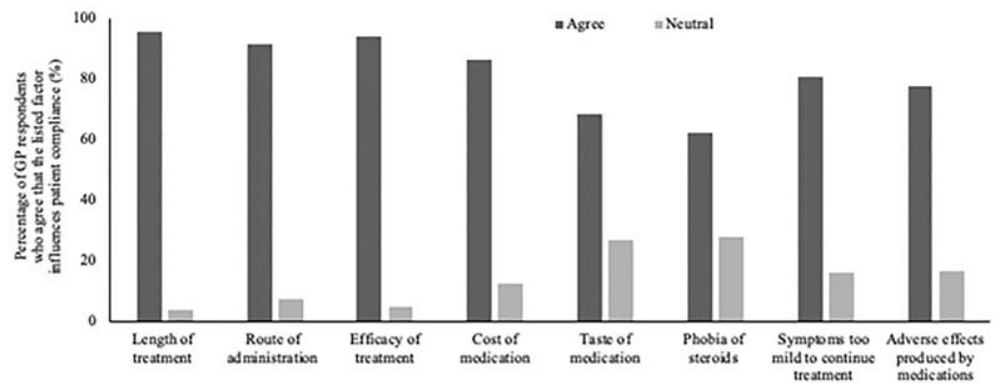

B

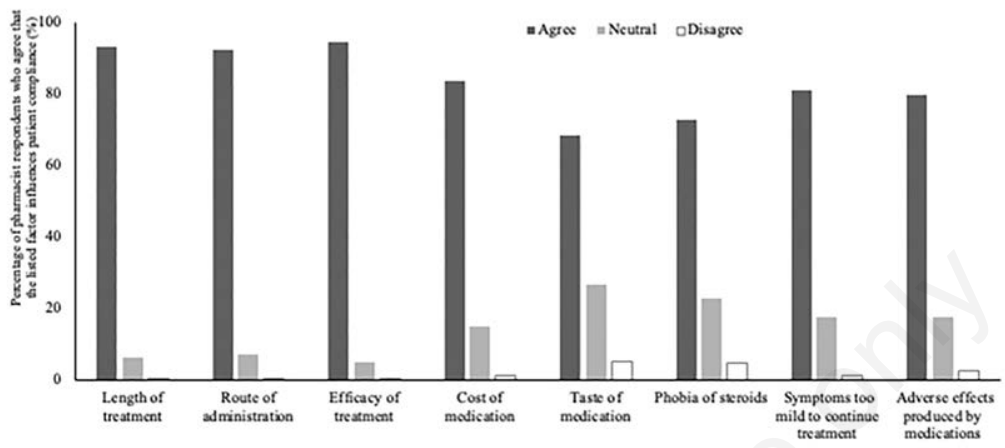

Figure 1. Factors influencing patient compliance to allergic rhinitis treatment. A) General practitioners; B) Pharmacists. Respondents were asked to review the listed factors that may influence patient compliance to allergic rhinitis treatment. The percentage of respondents who chose "Agree", "Neutral" or "Disagree" to specific factors is shown.
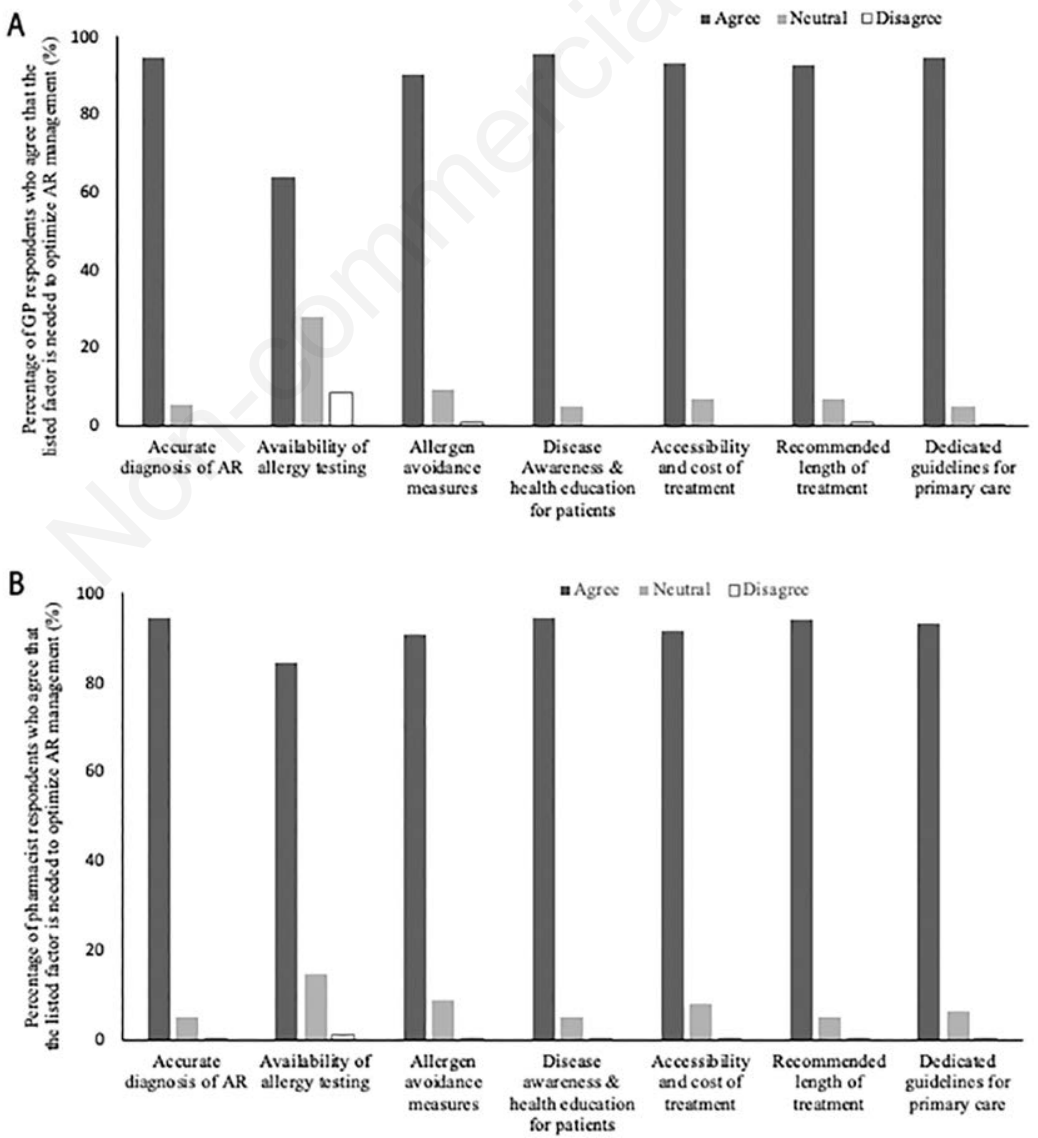

Figure 2. Factors needed to optimize AR management in primary care practice. A) General practitioners; B) Pharmacists. Respondents were asked to review the listed factors that are needed to optimize allergic rhinitis management in primary care practice. The percentage of respondents who chose "Agree", "Neutral" or "Disagree" to specific factors is shown. 
(GINA) guidelines (76.3\% vs 40.7\%; $<<0.001$ ) (Table 2). GPs also had more knowledge on differentiating rhinitis into AR and non$\mathrm{AR}$, as compared to pharmacists $(67.8 \%$ vs $49.3 \%$; $<<0.001)$, respectively (Table 2). A modest percentage of both GPs and pharmacists agree that the evaluation of asthma is necessary for AR $(80.1 \%$ and $65 \%)$, respectively (Table 2$)$.

Amongst those who have a moderate to full understanding ARIA (respondents who selected 'not sure' or 'yes'), a high percentage of both GPs and pharmacists still agreed that the ARIA guidelines are useful in the diagnosis and treatment of AR patients (Table 3). Additionally, both GPs and pharmacists agreed that AR can be classified into 'mild' or 'moderate/severe' depending on the severity of the symptoms and quality of life outcomes, aligned with ARIA guidelines (Table 3). Almost $80 \%$ of GPs and pharmacists agreed that the diagnosis of AR should be based upon the concordance between a typical history of allergic symptoms and allergy tests (Table 3 ).

\section{Discussion}

This survey presents findings on the attitudes and current practices of primary healthcare providers (GPs and pharmacists) managing AR in four ASEAN countries. The survey findings showed that a majority of GPs and only $50 \%$ of pharmacists rely on clinical history to identify AR, irrespective of the severity of the disease. Despite the many new treatment options available for AR, secondgeneration oral antihistamines remained the mainstay treatment option preferred by both GPs and pharmacists, with loratadine being the most recommended antihistamine option. Several factors and considerations were regarded as key to influencing patient compliance and optimizing AR management at a primary care level. Lastly, on guidelines, most GPs and pharmacists agreed that guidelines such as ARIA are useful in the treatment and diagnosis of AR.

Management of AR in primary care practice still heavily relies on clinical history for diagnosis. Clinical history is the most pre- ferred method by $95 \%$ of GPs in this study. Clinical history of AR, non-AR, chronic rhinosinusitis may be different, and thus clinical history may be helpful to differentiate AR from other upper respiratory diseases. The symptoms-based diagnosis of CRS has moderate reliability of around $60 \%$ [12-14]. Similarly, complete and detailed history taking can result in prompt AR diagnosis of up to $>80 \%$ [15]. However, clinical history is still inadequate in making a definitive diagnosis of type of allergies. For example, in a study conducted in the Philippines on 85 children, the sensitivity of clinical symptoms to diagnose AR was $>80 \%$ and specificity was $<30 \%$ compared to skin prick testing [15]. More pharmacists than GPs, agreed that allergy testing is needed to make a definitive diagnosis of AR (84.3\% of pharmacists $v s 63.8 \%$ of GPs; $<<0.001)$. The detection of specific IgE through skin prick or in vitro allergy testing is mandatory for diagnosing allergic disease. There are many differential diagnoses of AR, which are non-allergic (for example, vasomotor rhinitis, rhinitis medicamentosa, NARES and the very common infectious rhinitis), and are often mistaken for AR. Therefore, the risk of overdiagnoses of AR is present if we rely on clinical history alone. Nonetheless, the relevance, and implementation of allergy testing in primary care is controversial. Serum specific IgE testing is also expensive, not readily available and requires handling by laboratory technicians. As such, allergy testing is best done in tertiary settings by specialists. Thus, at a specialist level, allergy testing should be made more widely available and affordable for the specialist centers to utilize optimally. On other diagnostic methods, less than $15 \%$ of GPs chose imaging paranasal sinuses and nasal endoscopy. Imaging is not a recommended modality for diagnosis of AR and it is technically challenging to perform a nasal endoscopy examination at a primary care clinic. The majority of GPs would perform anterior rhinoscopy, which is relatively simpler to assess nasal congestion and nasal discharge. Despite varied preferences on diagnosis methods, it is an interesting observation that almost $80 \%$ of GPs and pharmacists agreed that the diagnosis of AR needs to be based upon the concordance between a typical history of allergic symptoms and allergy tests. Therefore, for primary care, the best

Table 3. GPs and pharmacists' agreement on statements pertaining to guidelines for allergic rhinitis management. The percentage of respondents who chose "Agree", "Neutral" or "Disagree" to specific statements listed is shown.

\begin{tabular}{|c|c|c|c|c|}
\hline & Responses & $\begin{array}{l}\text { GP n }(\%) \\
N=301 *\end{array}$ & $\begin{array}{l}\text { Pharmacists n (\%) } \\
\qquad \mathrm{N}=433^{*}\end{array}$ & $\begin{array}{l}\text { p-value, } \\
\text { comparing GP } \\
\text { to pharmacists }\end{array}$ \\
\hline The ARIA guidelines are useful in diagnosing AR patients & $\begin{array}{l}\text { Agree } \\
\text { Neutral } \\
\text { Disagree }\end{array}$ & $\begin{array}{l}273(90.7) \\
27(9) \\
1(0.3)\end{array}$ & $\begin{array}{l}361(83.4) \\
69(15.9) \\
3(0.7)\end{array}$ & 0.011 \\
\hline The ARIA guidelines are useful for the treatment of your AR patients & $\begin{array}{l}\text { Agree } \\
\text { Neutral } \\
\text { Disagree }\end{array}$ & $\begin{array}{l}280(93.6) \\
17(5.7) \\
2(0.7)\end{array}$ & $\begin{array}{c}368(85) \\
65(15) \\
0\end{array}$ & $<0.001$ \\
\hline $\begin{array}{l}\text { Aligned with the ARIA guidelines, allergic rhinitis can be sub-divided into } \\
\text { "intermittent" or "persistent" based on duration of symptoms }\end{array}$ & $\begin{array}{l}\text { Agree } \\
\text { Neutral } \\
\text { Disagree }\end{array}$ & $\begin{array}{l}266(88.4) \\
33(11) \\
2(0.7)\end{array}$ & $\begin{array}{l}348(80.4) \\
80(18.5) \\
5(1.2)\end{array}$ & 0.013 \\
\hline $\begin{array}{l}\text { Aligned with the ARIA guidelines, the severity of allergic rhinitis can be } \\
\text { classified as "mild" or "moderate/severe" depending on the severity } \\
\text { of the symptom and quality of life outcomes life outcomes }\end{array}$ & $\begin{array}{l}\text { Agree } \\
\text { Neutral } \\
\text { Disagree }\end{array}$ & $\begin{array}{c}276(91.7) \\
23(7.6) \\
2(0.7)\end{array}$ & $\begin{array}{c}357(82.4) \\
73(16.9) \\
3(0.7)\end{array}$ & $<0.001$ \\
\hline $\begin{array}{l}\text { The diagnosis of allergic rhinitis is based upon the concordance between } \\
\text { a typical history of allergic symptoms and allergy tests }\end{array}$ & $\begin{array}{l}\text { Agree } \\
\text { Neutral } \\
\text { Disagree }\end{array}$ & $\begin{array}{c}229(76.1) \\
58(19.3) \\
14(4.7)\end{array}$ & $\begin{array}{c}343(79.2) \\
84(19.4) \\
6(1.4)\end{array}$ & 0.035 \\
\hline
\end{tabular}

*Only respondents who stated "yes/ not sure" to the question "Do you know allergic rhinitis and its impact on asthma (ARIA) guidelines?" responded to these questions; AR, Allergic rhinitis; ARIA, allergic rhinitis and its impact on asthma; GP, general practitioner. 
approach may be to conduct more education programs to promote symptoms-based evaluation and escalation to specialists for diagnosis.

The survey results demonstrated that antihistamines, particularly $2^{\text {nd }}$ generation antihistamines, are still the mainstay of AR treatment in primary care practice within Malaysia, Philippines, Thailand and Indonesia. This correlated with a survey from the Philippines [11] that assessed the specialists' and GPs' attitudes and practices followed for the treatment of the AR patients. The authors showed that monotherapy, mainly antihistamines, was the preferred choice for mild AR treatment. For moderate-severe patients, both monotherapy (intranasal corticosteroid spray; INCS) and combination therapy with antileukotrienes, antihistamines, INCS were preferred. The choice of these therapeutic regimes was primarily attributed to efficacy and cost-effectiveness [11]. In contrast, the Current Allergic Rhinitis Experiences Survey (CARES) [16], which assessed the AR management practices followed by the primary healthcare professionals (HCPs) in the U.S., demonstrated that more than $80 \%$ of the HCPs stated intranasal corticosteroids as the gold standard for the treatment of AR. In this same study, HCPs also feedback that around $63 \%$ to $77 \%$ of patients can manage the disease after the treatment establishment, and around $70 \%$ of HCPs further agreed that over-the-counter (OTC) medicine should be tried before prescribed medicine for AR management [16]. It is a consensus that intranasal steroids are more effective than antihistamines. However, it is not suggested that intranasal steroids are the most cost-effective treatment options. Cost-effectiveness is especially relevant in ASEAN countries without ample public healthcare support such as the Philippines. The cost-effectiveness of antihistamines is a key contributing factor to primary care favoring the recommendations of antihistamines. Current research development has also demonstrated that second-generation antihistamines do have anti-inflammatory effects alongside their anti-histaminic effects, by decreasing the release of key cytokines and the migration of inflammatory cells [17]. Noteworthy, the survey results showed that there are still some primary care practitioners who would recommend $1^{\text {st }}$ generation antihistamines to AR patients. This may also be attributed to cost effectiveness, with $1^{\text {st }}$ generation typically priced cheaper than $2^{\text {nd }}$ generation antihistamines. More education is required at a primary care level to increase awareness of potential side effects associated with $1^{\text {st }}$ generation antihistamines.

The survey further revealed that non-drug treatment options such as saline douching and allergen avoidance are also preferred treatment options in both GP clinics and pharmacies. These nondrug treatment options are recommended in the ARIA guidelines as adjuncts to supplement the main treatments. However, these non-drug options have low evidence and should not replace standard treatments. The best treatment regimen is to employ multiple control measures comprising of allergen avoidance, mainstream treatments, and non-drug adjunct therapies.

The length and efficacy of treatment are viewed as essential by primary care for the long-term control of AR. Preference for the oral route of administration may also be due to the faster onset of action of oral $2^{\text {nd }}$ generation antihistamines (1-2 hours) compared with intranasal steroids (6 hours). Running out and dripping down of intranasal treatment resulting in patient discomfort is also a key consideration for patients. In addition, more pharmacists than GPs think that patients' phobia of steroids $(72.6 \%$ pharmacists $v s 62.5$ $\%$ GPs; $p<0.001$ ) is the other key factor influencing patient compliance. This may correlate with the high prescription/usage of antihistamines in primary care. Adverse events from corticosteroids treatment are real and can be life-threatening if not managed well. Although intranasal steroids today are generally tolera- ble in safety profiles, especially the new generation molecules, the evidence is still based off on safety studies of a trial period less than one year. There is currently no evidence demonstrating safety if patients were to use intranasal steroids longer than one year. This was also pointed out by the expert consensus statement in Malaysia, where it was noted that current guidelines are still vague in recommending the length of treatment of steroids in AR patients [9]. More clinical evidence is required to provide stronger guidance to primary care.

In this survey, $80.8 \%$ of GPs were aware of the ARIA guidelines, while only $48.4 \%$ of pharmacists were aware. This correlated with $81.7 \%$ of GPs and only $48.2 \%$ of pharmacists who know how to identify AR patients. Out of those who are aware of ARIA, $90.7 \%$ of GPs and $83.4 \%$ of pharmacists agreed that the ARIA guidelines are useful in the diagnosis of AR patients. Whilst the authors acknowledged the distinct roles of GPs and pharmacists in AR management (diagnosis versus dispensing respectively), it should be noted some patients visiting the pharmacy would have had AR previously diagnosed by physicians, some self-diagnosed and some without any diagnosis or inaccurate diagnosis (e.g., a viral infection or cold). Hence, pharmacists must be in good stead to identify the symptoms of AR and to recommend appropriate treatment [1]. The strong agreement from both GPs and pharmacists on the relevance of the ARIA guidelines validates the ongoing efforts to increase awareness and usage of ARIA. Several reasons may account for the pharmacist respondents having low awareness of the ARIA guidelines. Pharmacists are not exposed to the guidelines in their pharmacy curriculum, and dissemination of ARIA is mostly targeted to GPs as the emphasis is on diagnosis, an area restricted to medical doctors in most ASEAN countries. ARIA also has language barriers in some ASEAN countries. It will be most optimal to have either a translated version of ARIA or a national guideline (or ASEAN guideline), which is in line with ARIA. There is also an opportunity to leverage technology. Currently, an EU backed initiative termed as "Next Generation ARIA care pathways" is using digital technology to enable a patient-centered approach in allergy care in order to bridge the existing gap [18]. Western countries such as the U.S., UK, France, and Japan have brought ARIA into mobile applications such as MACVIA [19]. Care of AR patients are most optimal when we have a healthy ecosystem comprising of various healthcare professionals such as pharmacists, GPs, allergists, ENTs, nutritionists/dietitians even. Overall, ARIA has already adapted itself to meet the real world and to guide primary care practitioners. VAS score is introduced and replaced 'mild' and 'moderate to severe' for severity assessment. The stepwise approach has been developed with the aim that ARIA will be more practical [1].

There are several limitations to this study. Despite a large total sample size of 887 , this survey was an aggregate of 4 ASEAN countries, with an average of 82 GPs and 127 pharmacists per country. This may be regarded as a rather small sample size per country, and thus, the findings cannot be used to over-generalize each country. The survey results should be interpreted at an ASEAN level. Lastly, because the responses of the respondents were based on their own experience and perceptions, not on the objective assessment from the patient cohort or registry, the results of this study might be different from the real-world assessments.

In conclusion, our survey results have identified a need to strengthen the awareness and use of ARIA guidelines among primary care practitioners in the 4 ASEAN countries. Adherence to ARIA guidelines, choosing the appropriate treatment option and prioritizing factors that increase patient compliance may contribute to better management outcomes of AR at the primary care practice. 


\section{Acknowledgements}

The authors acknowledge Turacoz Healthcare Solutions (https://www.turacoz.com/) for the medical writing assistance.

\section{References}

1. Bousquet J, Khaltaev N, Cruz AA, Denburg J, Fokkens WJ, Togias A, et al. Allergic Rhinitis and its Impact on Asthma (ARIA) 2008 update (in collaboration with the World Health Organization, GA(2)LEN and AllerGen). Allergy 2008;63:S8160.

2. Tong MCF, Lin JSC. Epidemiology of allergic rhinitis throughout the world. In: Akdis CA, Hellings PW, Agache I, editors. EAACI Global atlas of allergic rhinitis and chronic rhinosinusitis. Zurich: European Academy of Allergy and Clinical Immunology; 2015. p. 62-3.

3. Katelaris CH, Lai CK, Rhee CS, Lee SH, Yun WD, LimVarona L, et al. Nasal allergies in the Asian-Pacific population: results from the allergies in Asia-Pacific survey. Am J Rhinol Allergy 2011;25:S3-15.

4. Wang DY, Chan A, Smith JD. Management of allergic rhinitis: a common part of practice in primary care clinics. Allergy 2004;59:315-9.

5. Brozek JL, Bousquet J, Agache I, Agarwal A, Bachert C, Bosnic-Anticevich S, et al. Allergic Rhinitis and its Impact on Asthma (ARIA) guidelines-2016 revision. J Allergy Clin Immunol 2017;140:950-8.

6. Bousquet J, Lund VJ, van Cauwenberge P, Bremard-Oury C, Mounedji N, Stevens MT, et al. Implementation of guidelines for seasonal allergic rhinitis: a randomized controlled trial. Allergy 2003;58:733-41.

7. Canonica GW, Triggiani M, Senna G. 360 degree perspective on allergic rhinitis management in Italy: a survey of GPs, pharmacists and patients. Clin Mol Allergy 2015;13:25.

8. Prepageran N, Wang de Y, Nair G, Maurer M. The status quo and unmet needs in the management of allergic rhinitis and chronic rhinosinusitis: a Malaysian perspective. Asia Pac Allergy 2014;4:142-8.

9. Baharudin A, Abdul Latiff AH, Woo K, Yap FB, Tang IP, Leong KF, et al. Using patient profiles to guide the choice of antihistamines in the primary care setting in Malaysia: Expert consensus and recommendations. Ther Clin Risk Manag 2019;15:1267-75.

10. Abdullah B, Kandiah R, Husna Nik Hassan NF, Ismail AF, Mohammad ZW, Wang DY. Assessment of perception, attitude, and practice of primary care practitioners towards allergic rhinitis practice guidelines: Development and validation of a new questionnaire. World Allergy Organization J 2020;13: 100482.

11. Navarro-Locsin CG, Romualdez JA. Attitudes, practices on allergic rhinitis of generalists and specialists in Philippine National Capital Region. Asia Pac Allergy 2015;5:203-9.

12. Tahamiler R, Canakcioglu S, Ogreden S, Acioglu E. The accuracy of symptom-based definition of chronic rhinosinusitis. Allergy 2007;62:1029-32.

13. Ferguson BJ, Narita M, Yu VL, Wagener MM, Gwaltney JM, Jr. Prospective observational study of chronic rhinosinusitis: environmental triggers and antibiotic implications. Clin Infect Di. 2012;54:62-8.

14. Tomassen P, Newson RB, Hoffmans R, Lotvall J, Cardell LO, Gunnbjornsdottir M, et al. Reliability of EP3OS symptom criteria and nasal endoscopy in the assessment of chronic rhinosinusitis--a GA(2) LEN study. Allergy 2011;66:556-61.

15. Castor MAR, Recto MT, Sumpaico MW. Correlation of skin prick test with symptoms and physical examinations finding in allergic rhinitis among Filipino Children. Phil J Allergy Asthma Immunol 2016;19:19-28.

16. Blaiss MS, Fromer LM, Jacob-Nara JA, Long RM, Mannion KM, Lauersen LA. Current Allergic Rhinitis Experiences Survey (CARES): Health-care practitioners' awareness, attitudes and practices. Allergy Asthma Proc 2014;35:316-22.

17. Marshall GD, Jr. Therapeutic options in allergic disease: antihistamines as systemic antiallergic agents. J Allergy Clin Immunol 2000;106:S303-9.

18. Bousquet J, Pham-Thi N, Bedbrook A, Agache I, AnnesiMaesano I, Ansotegui I, et al. Next-generation care pathways for allergic rhinitis and asthma multimorbidity: a model for multimorbid non-communicable diseases - Meeting Report (Part 1). J Thorac Dis 2019;11:3633-42.

19. Bousquet J, Schunemann HJ, Fonseca J, Samolinski B, Bachert C, Canonica GW, et al. MACVIA-ARIA Sentinel NetworK for allergic rhinitis (MASK-rhinitis): the new generation guideline implementation. Allergy 2015;70:1372-92.

Received for publication: 7 October 2020. Accepted for publication: 19 November 2020.

This work is licensed under a Creative Commons Attribution-NonCommercial 4.0 International License (CC BY-NC 4.0).

(C) Copyright: the Author(s), 2020

Licensee PAGEPress, Italy

Multidisciplinary Respiratory Medicine 2020; 15:726

doi:10.4081/mrm.2020.726 